Saudi Journal of Medical and Pharmaceutical Sciences

Abbreviated Key Title: Saudi J Med Pharm Sci

ISSN 2413-4929 (Print) |ISSN 2413-4910 (Online)

Scholars Middle East Publishers, Dubai, United Arab Emirates

Journal homepage: http://scholarsmepub.com/sjmps/

Original Research Article

\title{
Profile of Accidental Poisoning in Children: Studied at Urban Based Tertiary Care Centre
}

\author{
Sumita Pal ${ }^{1}$, Dipak Kumar Patra ${ }^{2 *}$, Basudha Roy ${ }^{3}$, Tanmoy Mazumdar ${ }^{4}$, G. K. De ${ }^{5}$, Natasha Biswas ${ }^{6}$ \\ ${ }^{1}$ Associate Professor, Department of Pediatrics, Calcutta National Medical College (Cnmch), India \\ ${ }^{2}$ Assoc. Prof, Cnmch, Dept. of Pediatrics, Calcutta National Medical College (Cnmch), India \\ ${ }^{3,4}$ Junior Resident (J. R),Cnmch. Dept of Pediatrics, Calcutta National Medical College (Cnmch), India \\ ${ }^{5}$ Prof. Dept of Pediatrics, Cnmch, Dept of Pediatrics, Calcutta National Medical College (Cnmch), India \\ ${ }^{6}$ J.R Cnmch, Dept of Pediatrics, Calcutta National Medical College (Cnmch), India
}

DOI: $\frac{10.36348 / \text { sjmps.2019.v05i12.015 }}{\text { | Received: 08.12.2019| Accepted: } 22.12 .2019 \text { | Published: } 30.12 .2019}$

*Corresponding author: Dr. Dipak Kumar Patra

\section{Abstract}

Objective: To study profile of accidental poisoning in $1 \mathrm{yr}-12 \mathrm{yr}$ children admitted at Paediatric ward in Calcutta national medical college \& hospital, (CNMCH) Kolkata from April 2018-March 2019 and their outcome. Method: All children admitted at CNMCH children ward from 1 to 12 year with accidental poisoning excluding all bites-including snake bite, scorpion sting etc. The age group, nature, type of poison, symptom complex \& response to therapy were studied. Result: 201 children of 9 month to 12 year with accidental exposure to poisoning admitted in a tertiary care centre. Common age group affected in the study is below 3 yrs $(75 \%)$.Boy child commonly affected \& common poisoning was kerosene oil $(52.2 \%)$ followed by turpentine oil $(14.9 \%)$. Among medication, poisoning (4.97\%) not only due accidental ingestion but due to overdosing. Other Rare causes of poisoning was Phenyl, Rat killer, Mosquito repellent/oil, bed bug killer etc. Mortality of the patient was $0.49 \% .30 \%$ cases (>14 days) suffering was prolonged. PICU management was needed in $1.99 \%$ cases. Conclusion: Most common cause of accidental poisoning was kerosene ingestion in rural children. Male children of toddler age group was involved commonly.

Keywords: Accidental poisoning, kerosene oil, medications, turpentine oil.

Copyright @ 2019: This is an open-access article distributed under the terms of the Creative Commons Attribution license which permits unrestricted use, distribution, and reproduction in any medium for non-commercial use (NonCommercial, or CC-BY-NC) provided the original author and source are credited.

\section{INTRODUCTION}

Accidental childhood poisoning is a major health problem $\&$ is responsible for serious mortality and morbidity $[1,2]$. Toxic exposure has become the most common cause of acute medical illness in many countries.

Toddlers \& pre school children are prone to accidental poisoning because of unsafe environment $\&$ child's inquisitive nature to explore the environment.

Parental ignorance to a great extent contribute for some of accidental poisoning cases. Since the poisonous non- edible substance are transferred from their original containers or those substances placed carelessly from the usual place of storage and also lack of adequate storage facility is often contributing factor.

Peak incidence of kerosene oil poisoning occurs at summer season due to faulty storage habit of kerosene oil at water bottle or beverage bottle .Thirsty children under 5 years can drink it unknowingly.

Medication toxicity not only due to accidental ingestion but also due to overdos [3]. Several factors interplay in the pattern of poisoning seen among children. The child's environment, the child's ability to explore ,parental beliefs, attitudes \& socio economic status of the family affected, all have basis in the type of poisoning to which our children are susceptible [3].

The present study is to focus the attention on the pattern of poisoning seen among hospitalized children. Predominantly belongs to vulnerable section of society.

\section{MATERIAL AND METHOD}

Study Area: Paediatric emergency \& in patient department of CNMCH, Kolkata. 
Study Population: All children admitted at Paediatric Ward of 9 Month -12 year age with accidental exposure to poisoning excluding all bites -animal bite, snake bite $\&$ insect contact.

Study Period: ONE year (April 2018- March 2019).

Sample Size: 201 children admitted at $\mathrm{CNMCH}$ (age group 9 months to 12 years).

Sample Design: Prospective Observational Study.

Inclusion Criteria: All children admitted at inpatient department of $\mathrm{CNMCH}$ with accidental exposure to poisoning from 9 month -12 years.

Exclusion Criteria: Below 9 month age and above 12 year and bites of animals /insects and insect contact.
Study Method: All children (201) admitted at Calcutta National Medical college, Kolkata without/with symptoms of poisoning during April 2018 to march 2019 were the subject of study. The age group, the coexisting factors, the nature of poison $\&$ the symptoms complex, response to therapeutic management were studied in details. Outcome of final Management observed.

\section{RESULTS}

201 (Two hundred and one) children were hospitalized over a period of one year with mild to severe symptoms of poisoning. The age group of paediatric patient affected, gender, nature of poison involved in this study is shown in Table-1.

Table-1: Types of poison, age and sex incidence (fig in parentheses includes the incidence)

\begin{tabular}{|l|l|l|l|l|l|l|l|}
\hline POISON & $\begin{array}{l}\text { TOTAL NO OF } \\
\text { CHILDREN }\end{array}$ & MALE & FEMALE & $\begin{array}{l}\text { 0-1 } \\
\text { YEAR }\end{array}$ & $\mathbf{1 - 3}$ YEAR & $\begin{array}{l}\text { 3-6 } \\
\text { YEAR }\end{array}$ & $\begin{array}{l}\text { 6-12 } \\
\text { YEAR }\end{array}$ \\
\hline 1.Kerosene oil & $105(52.2)$ & 72 & 33 & - & 80 & 21 & 4 \\
\hline 2.Turpentine oil & $30(14.9)$ & 18 & 12 & - & 15 & 12 & 3 \\
\hline 3.Medication & $10(4.97)$ & 7 & 3 & 3 & 3 & 2 & 2 \\
\hline 4.Deisel & $6(2.98)$ & 4 & 2 & - & 2 & 4 & - \\
\hline $\begin{array}{l}\text { 5.Mosquito } \\
\text { repellent oil }\end{array}$ & $6(2.98)$ & 5 & 1 & - & 4 & 1 & 1 \\
\hline 6.Rat killer & $6(2.98)$ & 4 & 2 & - & 3 & 3 & - \\
\hline 7.Cuso4 & $6(2.98)$ & 5 & 1 & - & 4 & 2 & - \\
\hline 8.Pesticide & $18(8.95)$ & 13 & 5 & - & 8 & 8 & 2 \\
\hline 9.Phenyl & $6(2.98)$ & 4 & 2 & - & 3 & 2 & 1 \\
\hline 10.Veg.oil & $3(1.49)$ & 2 & 1 & - & 3 & - & - \\
\hline 11.others & $5(2.48)$ & 5 & 0 & - & 2 & 3 & - \\
\hline & 201 & $139(69.1)$ & $62(30.9)$ & $3(1.49)$ & $127(63.18)$ & $58(28.85)$ & $13(6.46)$ \\
\hline
\end{tabular}

Table-1 shows that common poison involved in this study are kerosene oil ingestion (52.2\%) among total admission. (201 children) followed by turpentine oil ingestion (14.9\%) and pesticide ingestion (8.95\%).

Regarding kerosene ingestion, total 105 children admitted in one year study $(52.2 \%)$ of which common age group involved are 1 to 3 years (toddler age.) Total 80 toddler affected among 105 children (76.2\%). Male babies were commonly affected. The amount of kerosene oil ingestion had mild symptoms of toxicity like nausea, vomiting, pain abdomen, \& occasional loose stool and some of them presented with respiratory distress $(40 \%)$.

In study period, 6 children of toddler age group admitted 7 days after ingestion of poison with severe abdominal pain \& respiratory distress, needed prolonged hospital stay and intervention. Outcome was good.
Turpentine toxicity: Total 30 (14.9\%) children admitted in one year study period of which $18(60 \%)$ children were male $\&$ rest $12(40 \%)$ were female. 15 children $(50 \%)$ were of 1 to 3 years age group. Majority of them admitted with nausea \& vomiting \& outcome was good \& stay in hospital for observation was 72 hours. Only 2 out of 30 turpentine poisoning admitted for a prolonged period for abdominal pain 7 feed intolerance. Majority of the patient presented with nausea, vomitting \& diarrhoea.

Very few of them had serious toxic manifestation which need ventilator support (2/18 $* 100)=11.11 \%$. Two out of 18 pesticide poisoning need ventilator support \& aggressive therapy. Medication causing drug toxicity in our study were $4.97 \%$ (10 out of 201). 
Table-2: Nature of the medication involved in poisoning

\begin{tabular}{|l|l|}
\hline Name of the Drug & Number of cases Total (10) \\
\hline 1.Iron Tablet & $4(40 \%)$ \\
\hline 2.Benzadiazepine group of drug & $2(20 \%)$ \\
\hline 3.Phenothiazine & $2(20 \%)$ \\
\hline 4.Antihypertensive group of drug & $2(20 \%)$ \\
\hline
\end{tabular}

Table-2 Common age group of medication intake was $<6$ years. Iron intoxication was the cause of drug induced toxicity. Overdoses of iron preparation occur due to inadvertent intake of the medication.

Abdominal cramps, diarrhoea \& lethargy were the symptom complex in iron poisoning. Phenothiazinetoxicity associated extrapyramidal symptoms, oculogyric crisis, restlessness, ophisthotonus \& tremor. Majority of cases develop due to over dosage of medication given to suppress vomiting.

In our study period, among 201 children admitted in the hospital -only 1 patient presented with antihypertensive drug ingestion about 6-8 tablets \& observation of 48 hour showed no untoward effect on health.

2 out of 201 children admitted with ingestion of sleeping pill of Grandmother. Minor effect occur on them\& only symptomatic therapy needed. Discharge from hospital after 72 hours of observation without any significant health hazards. Mortality (1/201) $0.49 \%$ of hospitalized children outcome in our study. There is prolonged suffering>14 days admission needed \& intensive care management given for 7 days positively in pesticide poisoning (organophosphorus) .Out of 18 pesticide poisoning [4]. Cases needs ICU management (4/18) i.e. $22.2 \%$. One difficult case of paraquet poisoning which needs ventilatory support \& ultimately died due to renal failure.

\section{DISCUSSION}

In the present study, we got overall poisoning out of 201 children $127(63.18 \%$,) children are in the age group 1-3 years.

Sitaram et al., showed that majority of poisoning are in the age group of 1-3 years [4]. Another study Basu M et al., showed that $54.3 \%$ cases of poisoning are in the age group of 1-3 years of age [5].

Ghosh VB et al., showed that $80.7 \%$ of poisoning in the age group 1-5 years [6]. Sarkar AK et al., showed that out 134 cases children belong to age group of 1-3 years are main victims [7].

So my study is corroborating with above mentioned study. In my study, we got 139 male child $(69.1 \%)$ and 62 female child $(30.9 \%)$ out of the total 201 children. Gupta et al showed that poisoning in children is more common in male child in comparison to female child and male to female ratio is $2.5: 1$ [8].

Budhothaki et al., also showed that male children are more exposed with accidendal poisoning in compare to female children and male to female ratio was 1.4:1 [9].

So my study is collaborating with above mentioned study. It suggests that male child are more exposed to poisoning accident as they have more physical activity in compare to female child.

Khadgawat et al., showed that incidence of overall poisoning in children was $41.7 \%$ in summer and $33.7 \%$ in monsoon [10]. The kerosene poisoning occurs throughout the year but peaking in summer and my study is collaborating with this study in respect of kerosene poisoning.

Regarding type of poisoning, Sarkar et al., [7] showed that kerosene is the most common type of poisoning in compare to others. Basu $\mathrm{M}$ et al., [5] showed that out of 451 cases ingestion of kerosene constituted more than half $54.44 \%$ of cases.

My present study is corroborating with the above mentioned study. In present study, we got 18 pesticides poisoning cases, out of them 4 cases needed ICU management $(22.2 \%)$. One difficult case of paraquat poisoning needed ventilatory support and ultimately died. Mortality was only $0.49 \%$.

Abed M et al., a Saudi Arabian study showed that no case mortality due to poisoning in children [11]. This study corroborating close to our study as we found only one death out of 201children.

\section{CONCLUSION}

In our study, we conclude that poisoning in paediatric age group is common particularly in under 5year age group \& poisoning can be preventable by some of the following measures like:

- To keep all products (non edible) in their original containers \& to avoid in storing non-edible products in milk \& beverage bottles.

- To keep all non-edible products like kerosene, turpentine, phenyl etc separate from foods.

- To avoid giving medicine to children in dark room. 
- Children always mimic adult \& to avoid poisoning or overdose not to take medicine in front of under 5 year children.

- Educational training programme through mass media to teach the parents regarding health hazards of common non-edible household products. At commuminty level, baseline health care worker can also be trained in poison control and prevention.

\section{REFERENCES}

1. Santhsnakrishnan, B. R., \& Raju, V. B. (1972). Poisoning in childhood. Indian Journal Pediatr. 39:158-164.

2. Chatterjee, B., \& Banerjee, A. P. (1981). Accidental poisoning in children. Indian Pediatr. 18:157-162.

3. Ramesh, S., Srikanth, S., \& Parvathy, V. R. (1987). Poisoning in children. Indian Journal Pediatr, 54:179-773.

4. Sitaram, S., Sharma, U., \& Saxena, S. (1985). Accidental Poisoning in children. Indian Pediatr, 22:757-760.

5. Basu, M., Kundu, T. K., Dasgupta, M. K., Das, D. K., \& Saha, I. (2009). An experience from Tertiary Care hospital in Kolkata. Indian Journal of public health, 53(4).
6. Brata Ghosh, V., Jhamb, U., Singhal, R., \& Krishnan, R. (2013). Common childhood poisonings and their outcome in a tertiary care center in Delhi. The Indian Journal of Pediatrics, 80(6), 516-518.

7. Sarker, A. K., Ghosh, S., \& Barik, K. (1990). A study of accidental poisoning (in children) in a rural medical college hospital of West Bengal. Indian journal of public health, 34(3), 159-162.

8. Gupta, S., Govil, Y. C., Misra, P. K., Nath, R., \& Srivastava, K. L. (1998). Trends in poisoning in children: experience at a large referral teaching hospital. National Medical Journal of India, 11, 166-168.

9. Budhathoki, S., Poudel, P., Shah, D., Bhatta, N. K., Dutta, A. K., Shah, G. S., ... \& Singh, M. K. (2009). Clinical profile and outcome of children presenting with poisoning or intoxication: a hospital based study. Nepal Med Coll Journal, 11(3):170-175.

10. Khadgawat, R., Garg, P., Bansal, P., Arya, A., \& Choudhary, B. (1999). Accidental Poisoning. Indian Pediatrcs, 1555-1557.

11. Al Hazmi, A. M. (1998). Patterns of accidental poisoning in children in Jeddah, Saudi Arabia. Annals of Saudi medicine, 18(5), 457-459. 